ORIGINAL ARTICLE

\title{
Injuries and death of children in rollover motor vehicle crashes in the United States
}

\author{
F P Rivara, P Cummings, C Mock
}

Injury Prevention 2003;9:76-80

\begin{abstract}
Context: There is an increased awareness of the problem of rollover crashes, but few data on children involved in rollover crashes in the United States.

Objective: To determine: (1) the rates of rollover crashes involving children and the incidence of fatal injury; (2) the characteristics of crashes involving children; (3) the risk factors for children being in a rollover compared with a non-rollover crash; and (4) whether the risk of death is greater for children involved in crashes in sport utility vehicles (SUVs) or passenger cars.

Design: Retrospective cohort study.

Data: 1993 through 1998 crashes involving children younger than 16 years included in the Crashworthiness Data System or reported to the Fatality Analysis Reporting System.

Results: During the study period, 100.4 children per 100000 person-years were involved in a rollover crash, accounting for $10 \%$ of all children involved in crashes. The incidence of fatal injuries in rollover crashes was 3.4 per 100000 person-years. Sixty percent of children involved in rollovers were riding in SUVs. Among vehicles carrying children and involved in a crash, the adjusted relative risk of the crash being a rollover was 11.1 (95\% confidence interval (CI) 9.3 to 13.3) for SUVs compared with passenger cars. The adjusted relative risk of death was $1.8(95 \% \mathrm{Cl} 1.1$ to 2.8$)$ in a rollover crash and the relative risk of injury was $2.1(95 \% \mathrm{Cl} 1.1$ to 3.8$)$ compared with non-rollover crashes. However, the relative risk of death for children in SUVs which crashed was $0.4(95 \% \mathrm{Cl} 0.1$ to 2.5) compared with passenger cars which crashed.

Conclusions: Crashes involving children in SUVs were more likely to be rollover crashes than those involving passenger cars, and rollover crashes were associated with an increased risk of death and injury. However, the overall risk of death for children in a crash was not higher for children who crashed in an SUV compared to children who crashed in a passenger vehicle. Whether children are

safer overall in SUVs compared with other cars cannot be answered with the data used.
\end{abstract}

Dr F P Rivara, Harborv

Injury Prevention and

Research Center, Box

359960, 325 Ninth Ave,

Seattle, WA 91804, USA;

fpr@u.washington.edu

T he recent media attention to rollovers involving certain sport utility vehicles (SUVs) in the United States has increased the awareness of the problem of rollover crashes. In the United States in 1999, 10142 people were killed as occupants in automobile and light truck rollovers, including 8345 killed in single vehicle rollovers; 55\% of light vehicle occupant fatalities in single vehicle crashes involved rollover. ${ }^{1}$ The proportion of fatal crashes which involved a rollover differed by vehicle type: $46 \%$ of passenger car occupant fatalities in single vehicle crashes involved rollover, compared with $63 \%$ for pick-up trucks, $60 \%$ for vans, and $78 \%$ for SUVs.

Based on 1995-99 data, the National Highway Traffic Safety Administration (NHTSA) estimated that 241000 light vehicles rolled over each year (on average) in crashes reported to the police, and that 57000 occupants in rollover crashes received injuries. ${ }^{23}$ An estimated $16 \%$ of light vehicles in police reported single vehicle crashes rolled over. The estimated risk of rollover in a crash differed by vehicle type: $13 \%$ of cars and $14 \%$ of vans in police reported single vehicle crashes rolled over, compared with $24 \%$ of pick-up trucks and $32 \%$ of SUVs.

To our knowledge, there have been no studies of rollovers involving children, and no studies examining the factors which affect the risk of injury or death for children in rollover crashes. We undertook a study to answer the following questions: (1) what were the rates of children involved in rollover crashes in the United States and what was the incidence of fatal injury; (2) what were the characteristics of rollover crashes involving children; (3) given a crash involving a child, what factors were associated with the likelihood that the crash would be a rollover; and, (4) what was the overall risk, for a child, of dying if they crashed in a SUV compared with a passenger car?

\section{METHODS}

This was a retrospective cohort study of children younger than 16 years involved in crashes in the United States during 1993 through 1998.

\section{Data sources}

Data regarding crashes and non-fatal injuries were obtained from the NHTSA Crashworthiness Data System (CDS). ${ }^{2}$ The CDS collects detailed information on an annual sample of approximately 5000 police reported tow away crashes involving passenger vehicles each year in the United States. The CDS uses a three stage sampling scheme to make the data representative of all police reported tow away crashes in the United States. In the first stage, the United States was divided into 1195 primary sampling units (PSUs) composed of large cities, counties, or a contiguous group of counties. These were grouped into 12 categories by region and degree of urbanization and two PSUs were selected from each category with probability proportional to population. In the second stage, police agencies were selected from these 24 PSUs based on the number and type of crash reports they process annually.

Abbreviations: CDS, Crashworthiness Data System; $\mathrm{Cl}$, confidence interval; FARS, Fatality Analysis Reporting System; NHTSA, National Highway Traffic Safety Administration; PSU, primary sampling unit; SUV, sport utility vehicle 
Table 1 Number and annual rate of children 0-15 years in all motor vehicle crashes, United States 1993-98

\begin{tabular}{|c|c|c|c|c|}
\hline $\begin{array}{l}\text { Age (years) and } \\
\text { rollover status }\end{array}$ & $\begin{array}{l}\text { Actual counts in } \\
\text { the CDS data }\end{array}$ & $\begin{array}{l}\text { Estimated* number of } \\
\text { children in crashes } \\
\text { (in thousands) }\end{array}$ & $\begin{array}{l}95 \% \mathrm{Cl} \text { (in } \\
\text { thousands)* }\end{array}$ & $\begin{array}{l}\text { Rate per } 100000 \\
\text { per year }\end{array}$ \\
\hline All ages & 7003 & 3685 & 3077 to 4460 & 1008.5 \\
\hline Rollover & 745 & 367 & 306 to 556 & 100.4 \\
\hline Non-rollover & 6258 & 3318 & 2771 to 3904 & 908.1 \\
\hline $0-4$ & 2177 & 1095 & 884 to 1349 & 933.0 \\
\hline Rollover & 201 & 54 & 22 to 116 & 46.0 \\
\hline Non-rollover & 1976 & 1041 & 862 to 1233 & 887.0 \\
\hline $5-9$ & 1883 & 911 & 720 to 1157 & 800.0 \\
\hline Rollover & 171 & 46 & 17 to 110 & 40.4 \\
\hline Non-rollover & 1712 & 865 & 703 to 1047 & 759.4 \\
\hline $10-15$ & 2943 & 1679 & 1369 to 4927 & 1251.7 \\
\hline Rollover & 373 & 267 & 163 to 3303 & 199.1 \\
\hline Non-rollover & 2570 & 1412 & 1206 to 1624 & 1052.6 \\
\hline
\end{tabular}

Finally, crashes were selected from each police agency based on the type and severity of crash.

We used CDS records for 1993 through 1998 involving children younger than 16 years who were passengers (nondrivers) in passenger vehicles involved in crashes. Passenger vehicles are defined by NHTSA as cars, pick-up trucks, vans, and SUVs with a gross weight of 10000 pounds or less. ${ }^{2}$ SUVs are multipurpose vehicles designed to have off-road capabilities and include compact utility vehicles, large utility vehicles, utility station wagons, and utility type unknown. We excluded children who were in the open bed of pick-up trucks.

Injuries were determined by CDS investigators based on interviews with survivors, and medical and autopsy records. Injuries were classified using the abbreviated injury scale; ${ }^{4}$ we included injuries with an abbreviated injury scale score of 1 or greater.

Data on the number of fatal crashes were obtained from the Fatality Analysis Reporting System (FARS), which collects information regarding all crashes in the United States on public roads which result in a death within 30 days. ${ }^{1}$ While CDS data does allow estimates of the number of deaths, we used the FARS data instead because this includes all deaths occurring within 30 days rather than a sample of deaths. The number of children in the United States was obtained from census data. ${ }^{5}$

\section{Potential confounding variables}

We examined several potential confounders of the relationship of rollover status to risk of injury or risk of death. These included age (categorized into $0-4$ years, 5-9, 10-15), estimated vehicle speed (categorized into 0-19, 20-39, 40-59, $>60 \mathrm{mph}$ ), gender, restraint use (proper, improper, or none), seating position, posted speed limit (categorized as $<40 \mathrm{mph}$, 40-50 mph, >50 mph), vehicle type, and vehicle model year. The estimate of deceleration forces experienced by the occupants, a measure called delta-V (change in velocity), was used where applicable. In crashes in which the vehicle rolled over without first striking an object or being struck by another vehicle, the delta-V cannot be calculated. Some vehicles, however, roll over after first being struck by another vehicle or after first striking a fixed object, such as a tree. In this second group, a delta-V can be calculated. Therefore we included in all models an indicator variable for whether or not delta- $V$ could be calculated. In those crashes where it could be calculated, we also adjusted for the actual value of delta-V (in $\mathrm{km} / \mathrm{hour}$ ).

\section{Multiple imputation of missing data}

Information was often missing on estimated vehicle speed $(68.6 \%)$, delta-V where it could be calculated $(54.2 \%)$, and restraint use $(23.4 \%)$. Restricting analysis to cases without missing data leads to valid inferences only if data are missing completely at random. ${ }^{6}$ Because these characteristics appeared to be important potential confounders, multiple imputation was employed using an adaptation of the approximate Bayesian bootstrap method. ${ }^{78}$ Multiple imputation is based on the assumption that data are missing at random conditional on the values used to form the imputation groups. Therefore we used multiple imputation to create 10 sets of data which were identical in regard to known information, but could differ, one from another, on the imputed values for the missing information. To impute missing values for a variable, we identified those variables which were most strongly associated with the variable to be imputed, using either logistic regression or ordinal logistic regression in records with complete information. In order to preserve important relationships in the data, all imputation models included the outcome (survival or death) and the sampling weight (quintiles). In addition, model year, speed limit, rollover, age, and vehicle body type were used to impute vehicle speed; model year, vehicle weight, rollover, and injury severity score were used to impute delta-V; and child's age, ejection, model year, and seat position were used to impute restraint use.

\section{Analysis}

The CDS sample of crashes was a systematic sample of all crashes. We may think of this as a cohort study in which children entered the cohort at the time of the crash and experienced the study outcome, injury or death, moments later. We used Poisson regression to estimate the relative risk of either injury or death among children who were in a rollover crash compared with children in other crashes. Each potential confounder was entered into the regression individually, and kept in the model if it altered the relative risk estimate by more than $10 \% .^{9}{ }^{10}$ To obtain proper estimates and confidence limits, we used linearization methods that accounted for the sampling strata, weights, and clustering within sampling unit. ${ }^{11}{ }^{12}$ Separate, parallel analyses were then carried out on all 10 data sets. Point estimates from each analysis were averaged on the log scale and confidence intervals calculated by methods which accounted for both the variance within each data set and the variance between the data sets. ${ }^{7}$ To allow for modification of the effect of rollover by restraint use, we considered interaction terms between 
Table 2 Number of deaths and annual rate of deaths of children 0-15 in motor vehicle crashes, United States 1993-98

\begin{tabular}{lllll}
\hline $\begin{array}{l}\text { Age (years) and } \\
\text { rollover status }\end{array}$ & $\begin{array}{l}\text { Deaths of children } \\
\text { in crashes* }\end{array}$ & $\begin{array}{l}\text { Rate per } 100000 \\
\text { per year }\end{array}$ & $\begin{array}{l}\text { Crude case fatality } \\
\text { ratio } \times 100 t\end{array}$ & $95 \% \mathrm{Cl}$ \\
\hline $\begin{array}{l}\text { All ages } \\
\text { Rollover }\end{array}$ & 12431 & 3.4 & 0.3 & 0.3 to 0.4 \\
$\quad$ Non-rollover & 3947 & 1.1 & 1.1 & 0.7 to 1.3 \\
0-4 & 8484 & 2.3 & 0.3 & 0.2 to 0.3 \\
Rollover & 3695 & 3.2 & 0.3 & 0.3 to 0.4 \\
Non-rollover & 2756 & 0.8 & 1.7 & 0.8 to 4.3 \\
5-9 & 2.4 & 0.3 & 0.2 to 0.3 \\
Rollover & 2670 & 2.3 & 0.3 & 0.2 to 0.4 \\
Non-rollover & 1956 & 0.6 & 1.6 & 0.7 to 4.2 \\
& & 1.7 & 0.2 & 0.2 to 0.3 \\
10-15 & 6066 & 4.5 & 0.4 & 0.1 to 0.4 \\
Rollover & 2294 & 1.7 & 0.9 & 0.1 to 1.4 \\
Non-rollover & 3772 & 2.8 & 0.3 & 0.2 to 0.3 \\
\hline
\end{tabular}

*Data from the FARS.

tRatio of the number of deaths to the number of children in crashes $\times 100$. Estimated number of children in crashes from CDS data.

restraint use and rollover. Since these interaction terms were not statistically significant for either death $(p=0.9)$ or injury $(p=0.7)$, they were omitted from the models.

\section{RESULTS}

\section{Incidence of rollover crashes in the United States} involving children

During the study period, 100.4 children per 100000 personyears were involved in a rollover crash (table 1). Children involved in rollover crashes constituted 10.0\% (95\% confidence interval (CI) $6.9 \%$ to $18.1 \%$ ) of all children involved in crashes in the United States during 1993 through 1998 Involvement was most common among those 10 to 15 years old, among whom $15.9 \%$ of crashes were rollovers.

Table 3 Characteristics of children 0-15 years in rollover and non-rollover crashes, United States 1993-98; values are percent $(95 \% \mathrm{CI})$

\begin{tabular}{|c|c|c|}
\hline & $\begin{array}{l}\text { Rollover } \\
(n=367022)\end{array}$ & $\begin{array}{l}\text { Non-rollover } \\
(n=3314221)\end{array}$ \\
\hline \multicolumn{3}{|l|}{$\begin{array}{l}\text { Age of occupant } \\
\text { (years) }\end{array}$} \\
\hline $0-4$ & $14.7(6.0$ to 31.7$)$ & 31.4 (26.0 to 37.2$)$ \\
\hline $5-9$ & $12.6(5.6$ to 29.9$)$ & $26.1(21.2$ to 31.6$)$ \\
\hline $10-15$ & 72.8 (44.3 to 90.0 ) & 42.6 (35.4 to 49.0 ) \\
\hline \multicolumn{3}{|l|}{ Gender } \\
\hline Male & 73.8 (51.0 to 88.4$)$ & 46.7 (42.3 to 51.2 ) \\
\hline Female & 26.2 (1 1.5 to 49.0$)$ & $53.3(48.8$ to 57.7$)$ \\
\hline Restraint used & 50.3 (27.7 to 72.8$)$ & 79.2 (73.9 to 83.7 ) \\
\hline \multicolumn{3}{|l|}{ Vehicle body type } \\
\hline Passenger car & 24.5 (6.0 to 62.3 ) & $75.3(69.6$ to 80.3$)$ \\
\hline SUV & 60.3 (21.9 to 89.2 ) & 4.4 (3.1 to 6.1$)$ \\
\hline Minivan & 7.7 (2.4 to 22.0$)$ & $11.3(7.8$ to 15.0$)$ \\
\hline Van & 1.9 (1.1 to 3.3$)$ & $4.8(1.8$ to 12.3$)$ \\
\hline Light truck & $5.5(2.5$ to 11.5$)$ & 4.2 (2.2 to 8.0$)$ \\
\hline \multicolumn{3}{|c|}{ Vehicle manufacturer } \\
\hline US & 80.9 (58.5 to 92.7) & 71.7 (67.8 to 75.3$)$ \\
\hline Japan & 15.7 (6.4 to 33.7$)$ & 22.9 (19.4 to 26.7$)$ \\
\hline Germany & $1.9(0.3$ to 10.8$)$ & $1.6(0.7$ to 3.6$)$ \\
\hline Scandinavian & $0.1 \quad(0.1$ to 0.4$)$ & 2.3 (1.1 to 4.7$)$ \\
\hline Other European & $0.9(0.1$ to 6.8$)$ & $0.1 \quad(0$ to 0.2$)$ \\
\hline Other Asian & 0.5 (0.1 to 2.0$)$ & $1.4(0.6$ to 3.2$)$ \\
\hline \multicolumn{3}{|c|}{ Estimated vehicle speed (mph) } \\
\hline $0-19$ & $1.7(0.3$ to 9.2$)$ & 44.4 (40.1 to 48.9 ) \\
\hline 20-39 & 68.5 (20.3 to 94.9) & 30.1 (24.4 to 36.6$)$ \\
\hline $40-59$ & 13.0 (3.3 to 39.6$)$ & $19.9(11.5$ to 32.1$)$ \\
\hline $60+$ & $16.8(2.7$ to 59.5$)$ & 5.5 (2.5 to 11.9$)$ \\
\hline
\end{tabular}

The annual incidence of fatal injures to children from rollover crashes during 1993 through 1998 was 3.4 per 100000 (table 2). Among children fatally injured as motor vehicle occupants, $31.8 \%$ were killed in rollovers. As with all rollovers, rollover deaths were most common among the 10 to 15 year age group.

Characteristics of children involved in rollover crashes

Children involved in rollover crashes were more likely to be 10 to 15 years of age and male, compared with children involved in non-rollover crashes (table 3). They were less likely to use seat restraints. Sixty percent of children involved in rollovers were riding in SUVs compared with $4.4 \%$ of those in non-rollover crashes. Children in rollovers were less likely to be in vehicles traveling under $20 \mathrm{mph}$ and more likely to be in vehicles traveling between 20 and $39 \mathrm{mph}$. Among children in rollover crashes, $4.4 \%$ were ejected compared with $0.4 \%$ in non-rollover crashes.

\section{Risks of rollover compared to non-rollover crashes}

Among vehicles carrying children and involved in crashes, the risk of the crash being a rollover was 11.1-fold greater for SUVs and 1.7-fold greater for light trucks compared with crashes involving passenger cars, adjusted for vehicle weight, driver age and gender, vehicle speed, and model year (table 4).

Table 4 Factors associated with being in a rollover crash compared with being in a non-rollover crash, among children who were in any crash, United States 1993-98

\begin{tabular}{|c|c|c|}
\hline & Relative risk* & $95 \% \mathrm{Cl}$ \\
\hline \multicolumn{3}{|l|}{ Vehicle } \\
\hline SUV & 11.1 & 9.3 to 13.3 \\
\hline Light truck & 1.7 & 1.1 to 2.5 \\
\hline Passenger car & 1.0 & - \\
\hline Vehicle weight† & 0.95 & 0.9 to 1.0 \\
\hline Model year $¥$ & 0.96 & 0.9 to 0.99 \\
\hline Travel speed§ & 1.4 & 1.3 to 1.5 \\
\hline Female passenger & 0.6 & 0.4 to 0.9 \\
\hline Driver age & 0.97 & 0.95 to 0.99 \\
\hline \multicolumn{3}{|c|}{$\begin{array}{l}\text { *Adjusted for other variables in the model. } \\
\text { †Per } 10 \mathrm{~kg} \text { increment in weight. } \\
\text { ¥Per } 1 \text { year increment, base year } 1960 \text {. } \\
\S \text { Per } 6 \text { mph increment. } \\
\text { 『Per year of age. }\end{array}$} \\
\hline
\end{tabular}




\begin{tabular}{|c|c|c|}
\hline & $\begin{array}{l}\text { Relative } \\
\text { risk }\end{array}$ & $95 \% \mathrm{Cl}$ \\
\hline \multicolumn{3}{|l|}{ Vehicle } \\
\hline SUV & 0.4 & 0.1 to 2.5 \\
\hline Light truck & 0.4 & 0.2 to 1.2 \\
\hline Passenger car & 1.0 & - \\
\hline Female passenger & 1.6 & 0.8 to 3.2 \\
\hline \multicolumn{3}{|l|}{ Restraint use } \\
\hline Proper restraint use & 0.2 & 0.1 to 0.6 \\
\hline Improper restraint use & 0.5 & 0.2 to 1.5 \\
\hline No restraint use & 1.0 & - \\
\hline Vehicle speed* ${ }^{*}$ & 1.3 & 1.1 to 1.5 \\
\hline Delta-V calculatedt & 0.2 & 0.1 to 0.3 \\
\hline Delta-V amount $¥$ & 1.06 & 1.05 to 1.07 \\
\hline \multicolumn{3}{|c|}{$\begin{array}{l}\text { * In } 6 \text { mph increments. } \\
\text { This variable indicates whether delta-V could be } \\
\text { calculated in the crash or not (no/yes). } \\
\text { FThis is the actual value for delta- } V \text { as a } \\
\text { continuous variable in kph. }\end{array}$} \\
\hline
\end{tabular}

Heavier vehicles and more modern vehicles were less likely to be in rollovers than non-rollover crashes. The risk of the crash being a rollover increased 1.4-fold for each $6 \mathrm{mph}$ increase in travel speed at the time of the crash.

Among rollover crashes, $65.1 \%$ were less than 360 degree turns. Only 2.3\% were end-over-end rollovers.

\section{Risk of injury and death}

Among children involved in rollovers, 1.1\% died (95\% CI 0.7\% to $1.3 \%)$. The crude case fatality proportion for non-rollovers was significantly lower, $0.3 \%$ ( $95 \%$ CI $0.2 \%$ to $0.3 \%$ ). Children in each age group had higher case fatality proportions in rollover compared with non-rollover crashes (table 2). Among children in rollovers, $4.2 \%$ were injured ( $95 \%$ CI $3.5 \%$ to $4.9 \%$ ), compared with $3.2 \%$ (95\% CI $2.3 \%$ to $4.5 \%$ ) of children in non-rollover crashes.

After adjusting for delta-V, estimated speed, seat restraint use, type of vehicle and age of the child, being in a rollover crash, compared with all other crashes, was associated with a twofold increase in the risk of death (relative risk 1.8, 95\% CI 1.1 to 2.8 ) and risk of injury (relative risk $2.1,95 \%$ CI 1.1 to 3.8).

\section{Risk of death in SUVs}

Because SUVs were associated with an increased risk of being in a rollover crash compared with being in a non-rollover crash, and because being in a rollover crash was associated with an increased risk of death, we sought to determine if the risk of death in a crash was increased or decreased for children in SUVs which crashed compared with passenger cars which crashed. Adjusted for occupant restraint use and gender, vehicle speed and delta-V, the relative risk of death was $0.4(95 \% \mathrm{CI}$ 0.1 to 2.5 ) for occupants of SUVs compared with occupants of passenger cars (table 5). However, the sample of deaths in SUVs was small, and the confidence limits were wide and included 1 .

\section{DISCUSSION}

We found that about one of every 10 children in crashes in the United States during 1993 through 1998 was in a rollover crash. The risk of death to children in rollover compared with non-rollover crashes was increased by $80 \%$ and the risk of injury was more than doubled. Sixty percent of children in rollovers were riding in an SUV compared with $4.4 \%$ of children in a non-rollover crash. The adjusted risk that the crash would be a rollover was 11.1 -fold greater for SUVs than for passenger cars. However, since rollover crashes are much less common than non-rollover crashes, and since mass of the vehicle is directly related to survival, taking all crashes into consideration, the risk of death was not statistically different for children involved in crashes in SUVs compared to passenger vehicles.

Rollovers accounted for $3.7 \%$ of all crashes in the United States, $5.8 \%$ of injuries, and $28.3 \%$ of occupant fatalities. ${ }^{12}$ There are no prior data on risk of injury or death to children in rollovers.

The tendency of SUVs to be involved in rollover crashes has been the subject of recent attention. NHTSA uses the static stability factor, defined as one half the track width of a vehicle divided by the height of its center of gravity, as a measure of rollover risk. ${ }^{3}$ NHTSA has estimated that the risk of a rollover per single vehicle crash is six times greater for a vehicle with an static stability factor of 1.00 compared with a vehicle with an static stability factor of 1.53 (the range of the observed data) based on a linear regression model. SUVs have a static stability factor generally less than 1.15 , while in passenger cars it is generally greater than 1.35 . Our study indicates that among children who were in a crash, those in a SUV were about 11 -fold more likely to be in a rollover compared with children in a passenger car. However, the overall risk of death for children in SUVs which crashed compared with children in passenger cars which crashed was not increased and may in fact be lower.

The higher risk of rollover for 10 to 15 year old children is unlikely to be related to the age of the driver with whom these children ride. We found no effect in our estimates after controlling for age of the driver. In contrast, NHTSA reported that driver age less than 25 years was a significant predictor of the risk of a crash being a rollover crash compared with being a non-rollover crash. ${ }^{3}$

There are a number of possible limitations to our data that should be considered in interpreting our results. The number of fatal injuries involving children in SUVs was small and therefore our estimate of the relative risk of death in a SUV that crashed, compared with a passenger car that crashed, was very imprecise. While there may be some misclassification of seat restraint use, CDS data do not rely on police reports. The information on seat restraint use is based primarily on inspection of the belt for evidence of loading forces on the belt in the crash or evidence that the belt was cut by the paramedics indicating that the belt was worn by the occupant, supplemented by medical and autopsy records and confidential interviews with survivors.

In conclusion, among children who were in a crash, the likelihood that the vehicle would rollover was about 11 -fold greater if it was a SUV compared with a passenger car. In addition, in a rollover crash, compared with other crashes, the risk of death and injury was greater. However, the overall risk of death for children in a crash was not higher for children who crashed in a SUV compared to children who crashed in a passenger vehicle. Whether children are safer overall in SUVs compared with other cars cannot be answered with the data we used.

\section{IMPLICATIONS FOR PREVENTION}

The risk of injury or death for children in motor vehicle crashes was approximately doubled if the vehicle rolled over during the crash. Among vehicles which were involved in crashes, SUVs had an about 11 -fold greater risk of rolling over than passenger cars. However, SUVs generally are larger, heavier vehicles than passenger cars and risk of death has been shown previously to be inversely related to the mass of the vehicle in which the occupant is riding..$^{13}{ }^{14}$ Many motor vehicle crashes are frontal, non-rollover crashes; we found that only about $10 \%$ of crashes with child occupants involved rollovers. Thus, the overall risk of death for children involved 


\section{Key points}

- During 1993 to 1998 , rollover crashes accounted for $10 \%$ of all crashes involving children in the United States.

- Sixty percent of children involved in rollovers were riding in sports utility vehicles compared to $4 \%$ of children involved in non-rollover crashes.

- The risk of death in a rollover crash was 1.8-old greater and the risk of injury was 2.1-fold greater than for non-rollover crashes.

in a motor vehicle crash was not increased in children riding in SUVs that crashed compared with children riding in other cars. Among SUVs that crashed, the increased risk of death from being involved in a rollover may be outweighed by the lower risk of death due to being in a heavier vehicle in non-rollover crashes.

This study leaves unanswered the question of whether SUVs are in general safer or less safe than other cars because we did not have data to address the risk of crashing in all vehicles traveling on the road.

\section{ACKNOWLEDGEMENTS}

This study was funded by Grant No DTN H22-99-H-1744 from the National Highway Traffic Safety Administration and by Grant No CCR 002570-16-1 from the Centers for Disease Control and Prevention. We would also like to acknowledge the help of Chris Mack in data analysis

\section{Authors' affiliations}

F P Rivara, Harborview Injury Prevention and Research Center and Departments of Pediatrics and Epidemiology, University of Washington
P Cummings, Harborview Injury Prevention and Research Center and Department of Epidemiology, University of Washington

C Mock, Harborview Injury Prevention and Research Center and Departments of Epidemiology and Surgery, University of Washington

\section{REFERENCES}

1 National Highway Traffic Safety Administration. Traffic safety facts 1998: a compilation of motor vehicle crash data from the Fatality Analysis Reporting System and the General Estimates System. Washington, DC: NHTSA, 1999.

2 National Highway Traffic Safety Administration. National Automotive Sampling System. Crashworthiness Data System 1995-1997. Vol DOT HS 809 203. Washington, DC: US DOT, NHTSA, February 2001.

3 National Highway Traffic Safety Administration. Available at: http://www.nhtsa.dot.gov/cars/rules/rulings/roll_resistance/ index.html\#N_2, 2001.

4 Association for the Advancement of Automotive Medicine. The abbreviated injury scale. Des Plaines, IL: AAAM, 1990.

5 Centers for Disease Control and Prevention. Available at: http://wonder.cdc.gov, 2001.

6 Greenland S, Finkle WD. A critical look at methods for handling missing covariates in epidemiologic regression analysis. Am J Epidemiol 1995:142:1255-64.

7 Little RJA, Rubin DB. Statistical analysis with missing data. New York: John Wiley, 1987

8 Rubin DB. Multiple imputation for non-response in surveys. New York: John Wiley, 1987.

9 Mickey RM, Greenland S. The impact of confounder selection criteria on effect estimation. Am J Epidemiol 1989;129:125-37.

10 Rothman KJ, Greenland S. Modern epidemiology. Philadelphia: Lippincott-Raven, 1998.

11 Statcorp. Stata statistical software: release 6.0. College Station, TX: Stata Corporation, 1999.

12 Levy PS, Lemeshow S. Sampling of populations: methods and applications. New York: John Wiley, 1999.

13 Evans L, Frick MC. Mass ratio and relative driver fatality risk in two-vehicle crashes. Accid Anal Prev 1993;25:213-24.

14 Evans L, Frick MC. Car mass and fatality risk: has the relationship changed? Am J Public Health 1994;84:33-6. 